\title{
Role of biologics in intractable urticaria
}

This article was published in the following Dove Press journal:

Biologics:Targets and Therapy

13 April 2015

Number of times this article has been viewed

\section{Andrew Cooke' \\ Adeeb Bulkhi ${ }^{1,2}$ \\ Thomas B Casale \\ 'Department of Internal Medicine, Division of Allergy and Immunology, University of South Florida, Tampa, FL, USA; ${ }^{2}$ Department of Internal Medicine, College of Medicine, Umm Al-Qura University, Makkah, Saudi Arabia}

Video abstract

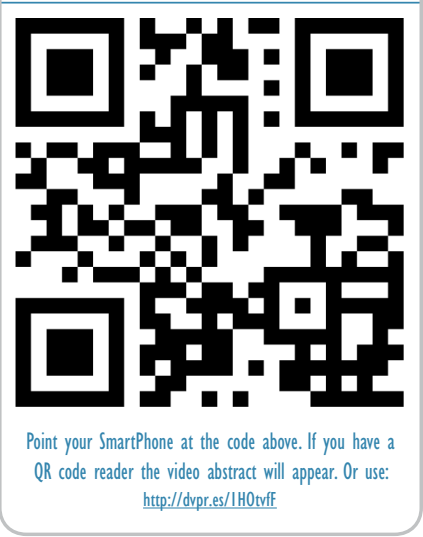

Correspondence: Thomas B Casale Department of Internal Medicine, Division of Allergy and Immunology, University of South Florida, I290 I Bruce B Downs Blvd, MDC 19, Tampa, FL, USA $\mathrm{Tel}+$ I 8139727662

Fax + I 8I3910 404|

Email tbcasale@health.usf.edu
Abstract: Chronic urticaria $(\mathrm{CU})$ is a common condition faced by many clinicians. $\mathrm{CU}$ has been estimated to affect approximately $0.5 \%-1 \%$ of the population, with nearly $20 \%$ of sufferers remaining symptomatic 20 years after onset. Antihistamines are the first-line therapy for CU. Unfortunately, nearly half of these patients will fail this first-line therapy and require other medication, including immune response modifiers or biologics. Recent advances in our understanding of urticarial disorders have led to more targeted therapeutic options for CU and other urticarial diseases. The specific biologic agents most investigated for antihistamine-refractory CU are omalizumab, rituximab, and intravenous immunoglobulin (IVIG). Of these, the anti-IgE monoclonal antibody omalizumab is the best studied, and has recently been approved for the management of CU. Other agents, such as interleukin-1 inhibitors, have proved beneficial for Schnitzler syndrome and cryopyrin-associated periodic syndromes (CAPS), diseases associated with urticaria. This review summarizes the relevant data regarding the efficacy of biologics in antihistamine-refractory CU.

Keywords: chronic urticaria, omalizumab, intravenous immunoglobulin, anakinra, canakinumab

\section{Introduction}

Chronic urticaria (CU), also known as chronic spontaneous urticaria (CSU), is defined as spontaneous appearance of wheals, angioedema, or both, for greater than 6 weeks. ${ }^{1}$ CU impacts patients with intense pruritus, disfiguring wheals, emotional disturbance, and difficulties with daily activities, all of which can be debilitating and impact on quality of life. ${ }^{2-5} \mathrm{CU}$ has been estimated to affect as high as $0.5 \%-1 \%$ of the population and nearly $20 \%$ of sufferers remain symptomatic 20 years after onset. ${ }^{6-8}$ First-line treatment for $\mathrm{CU}$ is second-generation antihistamines, which are often required at high doses. ${ }^{9}$ However, antihistamines may fail to adequately control $\mathrm{CU}$ in nearly half of patients. ${ }^{8,10}$ To achieve adequate control, a variety of biologic agents have been utilized. The biologic agents discussed in this review for use in antihistamine-refractory CU are omalizumab, rituximab, intravenous immunoglobulin (IVIG), and the TNF- $\alpha$ inhibitors infliximab, adalimumab, and etanercept. Anakinra will be discussed for its use in Schnitzler syndrome, a syndrome presenting with nonpruritic urticaria, bone pain, and intermittent fevers. ${ }^{9}$ Canakinumab will be discussed for its usage in the cryopyrinassociated periodic syndromes (CAPS) and systemic juvenile idiopathic arthritis (SJIA). The focus of this paper is on the evidence for biologics utilized in CU.

\section{Omalizumab}

Omalizumab is a recombinant humanized monoclonal anti-IgE antibody that binds to the $\mathrm{C}$ epsilon 3 domain of $\operatorname{IgE}$ (the site of high-affinity $\operatorname{IgE}$ receptor binding) and 
inhibits it from binding to the cell receptor. ${ }^{11,12}$ Originally approved for treatment of allergic asthma, omalizumab has been shown to be efficacious in the treatment of CU. ${ }^{9}$ While the exact cause of $\mathrm{CU}$ is not entirely known, a large proportion of patients have autoantibodies to the alpha chain of the high-affinity receptor FceR1 or to IgE. ${ }^{13}$ These autoantibodies are thought to cause mast cell activation, leading to $\mathrm{CU} .{ }^{14}$ Omalizumab is believed to work in part by affecting this pathway and by binding free IgE, thereby leading to a reduction of free IgE levels and consequently, decreased expression of FceRI receptors on mast cells, basophils, and dendritic cells. ${ }^{15-17}$ Additionally, mast cell survival is theorized to be contingent on IgE-FceRI-dependent pathways. ${ }^{18}$ The exact mechanisms are likely more complex, with further research needed to elucidate them.

The initial evidence supporting the use of omalizumab in $\mathrm{CU}$ was seen in patients with allergic asthma and concomitant urticaria. The first documented case was of a subject with extrinsic asthma and cold urticaria. Treatment with omalizumab resulted in complete response after 5 months of therapy. ${ }^{19}$ This was followed by multiple other case reports extolling the efficacy of omalizumab on urticaria. ${ }^{16,20-23}$ Soon, case reports had shown omalizumab to be efficacious in a variety of physical urticarial diseases including cholinergic urticaria, cold urticaria, delayed pressure urticaria, dermatographia, and solar urticaria. ${ }^{24-28}$

Kaplan et al performed the first prospective trial of omalizumab in $\mathrm{CU} .{ }^{29}$ They studied autoimmune urticaria based on a positive basophil histamine release assay and/or a positive autologous skin test, as well as a total serum IgE of $\leq 700 \mathrm{IU} / \mathrm{mL}$ in 12 patients. With weight- and IgE levelbased omalizumab dosage, the response rate was approximately $92 \%$. Seven patients had complete resolution and four exhibited symptoms reduction. Maurer et al evaluated the efficacy of omalizumab in CU patients with IgE against thyroperoxidase (TPO). ${ }^{30}$ Subjects were selected based on elevated serum IgE anti-TPO and total IgE level. The doses were individualized based on body weight and total IgE. After 24 weeks of omalizumab treatment, more than $50 \%$ became symptom free.

The success of the above small prospective trials was soon followed by a Phase II prospective, randomized, doubleblinded, placebo-controlled dose-ranging trial. ${ }^{31}$ In this trial, subjects were randomized to $75 \mathrm{mg}, 300 \mathrm{mg}$, or $600 \mathrm{mg}$ of omalizumab or placebo. Subjects had antihistaminerefractory chronic idiopathic urticaria (CIU) for more than 3 months. Ninety subjects were enrolled and randomized to either one of the omalizumab arms or placebo. After a 2-week screening and run-in, subjects were given a single subcutaneous injection. They were monitored for 4 weeks and subsequently followed for 12 more weeks. At the end of the treatment phase, the $75 \mathrm{mg}$ dose showed no difference from placebo, whereas both the $300 \mathrm{mg}$ and $600 \mathrm{mg}$ doses showed improvement over placebo. Additionally, $36 \%$ of patients in the $300 \mathrm{mg}$ arm and $28.6 \%$ of patients in the $600 \mathrm{mg}$ arm achieved complete remission.

Following the impressive results of the above trials, three large Phase III clinical trials were performed. The first trial published was ASTERIA II, a randomized, placebocontrolled, double-blind study performed to evaluate the efficacy and safety of omalizumab in moderate-to-severe CU refractory to licensed doses of H1-antihistamines. ${ }^{32}$ Subjects had at least 6 months of CIU/CSU and a weekly urticaria activity score (UAS7) of at least 16 (scale ranging from 0-42), with higher scores being more severe. Subjects were randomized to $75 \mathrm{mg}, 150 \mathrm{mg}$, or $300 \mathrm{mg}$ of omalizumab or placebo at 4-week intervals followed by a 16-week observation period. Both the $150 \mathrm{mg}$ and $300 \mathrm{mg}$ doses of omalizumab showed a significant improvement over baseline, but not the $75 \mathrm{mg}$ dosage of omalizumab or placebo. The rate of any adverse events was similar across the four groups: $59 \%$ in the $75 \mathrm{mg}$ group, $67 \%$ in the $150 \mathrm{mg}$ group, $65 \%$ in the $300 \mathrm{mg}$ group, and $61 \%$ in the placebo group. There was a clear dose-dependent effect, with the proportions of patients who were completely free of hives and angioedema (UAS7 score of 0 ) being $5 \%$ in the placebo group, $16 \%$ in the group receiving $75 \mathrm{mg}$ of omalizumab, $22 \%$ in the group receiving $150 \mathrm{mg}$ of omalizumab, and $44 \%$ in the group receiving $300 \mathrm{mg}$ of omalizumab.

The next large trial published on omalizumab was Glacial, a large randomized, double-blinded, placebocontrolled trial evaluating the safety and efficacy of 24 weeks of $300 \mathrm{mg}$ of omalizumab compared to placebo. ${ }^{33}$ To enroll, subjects were required to have CU/CSU refractory to H1-antihistamines at up to four times the licensed doses; additionally, patients were allowed to have been on an H2-blocker and/or leukotriene antagonist. A total of 336 subjects were randomized to either placebo or $300 \mathrm{mg}$ omalizumab. Unlike prior trials, patients were instructed to continue the pretrial dosage of antihistamines, $\mathrm{H} 1$ and $\mathrm{H} 2$, and leukotriene antagonists, with omalizumab as addon therapy. As with prior trials, the weekly itch score was used to determine the efficacy of omalizumab. At week 12, $33.7 \%$ of patients in the omalizumab arm were pruritus and urticaria free, while only $4.8 \%$ of subjects in the placebo arm were pruritus and urticaria free. In terms of the primary 
safety endpoints, the overall incidence of adverse events and serious adverse events was similar between omalizumab and placebo recipients. Of the adverse events noted, headache and upper respiratory tract infections appeared more frequently in the omalizumab cohort than in the placebo group. As seen with the ASTERIA II trial, upon discontinuation of the medication, subjects' urticarial activity score drifted upward to equal the placebo's level.

The results of ASTERIA I, a 24-week randomized, double-blinded, placebo-controlled study evaluating both the efficacy and safety of omalizumab as an add-on therapy, was published in July $2014 .{ }^{27}$ The design of ASTERIA I was similar to ASTERIA II, except that the treatment period was 24 weeks, instead of 12 weeks. Three hundred and nineteen subjects were randomized to either 24 weeks of $75 \mathrm{mg}$, $150 \mathrm{mg}$, or $300 \mathrm{mg}$ omalizumab or placebo. By week 12, all omalizumab arms experienced a significant improvement in weekly pruritus score over baseline, while the placebo arm did not, with the $300 \mathrm{mg}$ omalizumab arm demonstrating the greatest improvement. Additionally, over four times as many subjects in the omalizumab $300 \mathrm{mg}$ arm achieved complete remission than in the placebo arm. Subjects in the omalizumab $300 \mathrm{mg}$ arm showed sustained benefit through week 24 while in the active phase of the trial. Once again, the urticarial activity increased to values similar to placebo upon follow-up. The safety profile of this study showed 5\% of subjects in the placebo arm experienced a drug-related adverse event; in the omalizumab arms, these were slightly higher, with $8.6 \%$ in the $75 \mathrm{mg}$ arm, $10.3 \%$ in the $150 \mathrm{mg}$ arm, and $17.3 \%$ in the $300 \mathrm{mg}$ arm. A recent analysis pooled the data of these three large trials and showed that the efficacy of omalizumab was consistent in patients with $\mathrm{CU}$ with different underlying therapy, as shown in Figures $1-3 .^{34}$

On the basis of the large Phase III trials, the US Food and Drug Administration (FDA) approved the use of omalizumab $150 \mathrm{mg}$ or $300 \mathrm{mg}$ every 4 weeks in CU/CSU for patients 12 years and older who remain symptomatic despite H1-antihistamines. When omalizumab is discontinued in successfully treated patients with CU/CSU or physical urticarias, relapse may occur. ${ }^{35}$ In these patients, retreatment with omalizumab was reported to be effective in again treating their symptoms..$^{35}$ Critical issues yet to be defined include mechanisms of action, duration of therapy to modify or cure the disease, up-and-down dose-titration recommendations, identification of likely responders, and effects in failures of other biologics (Table 1).

\section{Intravenous immunoglobulin}

IVIG is human immunoglobulin prepared by pooling plasma obtained from thousands of healthy donors. ${ }^{36}$ IVIG is used

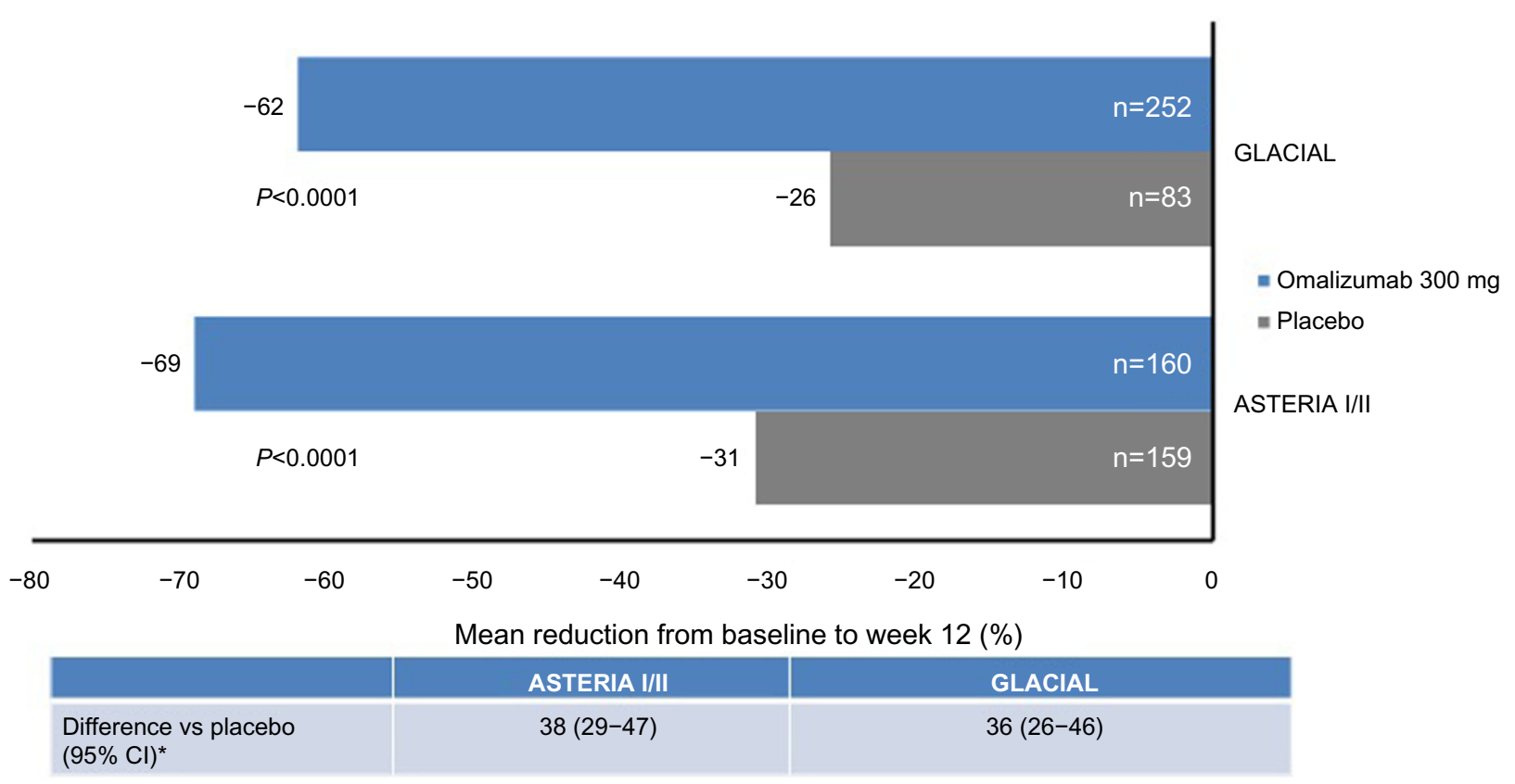

Figure I Percentage reduction from baseline to week 12 in weekly itching severity score.

Note: Significantly greater reductions from baseline to week 12 in weekly itching severity score observed with omalizumab 300 mg vs placebo in both the pooled ASTERIA I/II and GLACIAL studies. *Treatment difference in least squares means (LSM) relative to placebo. Data from Bernstein JA, Saini SS, Maurer M, et al. Efficacy of omalizumab in patients with chronic idiopathic/spontaneous urticaria with different background therapy: post hoc analysis of ASTERIA I, ASTERIA II, and GLACIAL studies. J Allergy Clin Immunol. 20I4; I33(2 Suppl):ABI I $7 .^{34}$

Abbreviation: $\mathrm{Cl}$, confidence interval. 


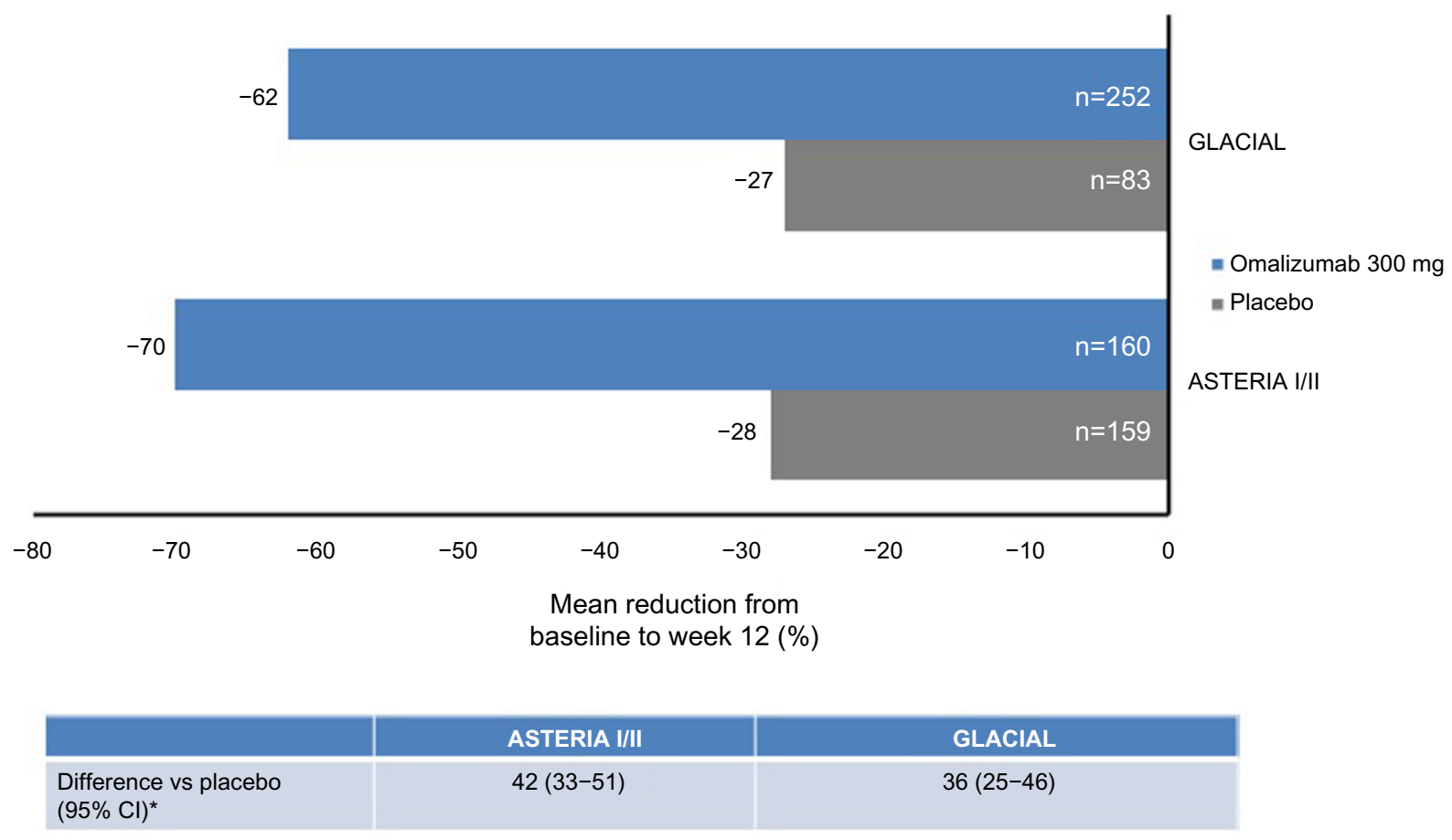

Figure 2 Percentage reduction from baseline to week 12 in weekly number of hives score.

Note: The reductions from baseline to week 12 in the weekly number of hives score observed with omalizumab 300 mg in the pooled ASTERIA I/II and GLACIAL studies were similar and significantly greater than with placebo. *Treatment difference in least squares means (LSM) relative to placebo. Data from Bernstein JA, Saini SS, Maurer M, et al. Efficacy of omalizumab in patients with chronic idiopathic/spontaneous urticaria with different background therapy: post hoc analysis of ASTERIA I, ASTERIA II, and GLACIAL studies. J Allergy Clin Immunol. 20I4;133(2 Suppl):ABI I7. ${ }^{34}$

Abbreviation: $\mathrm{Cl}$, confidence interval.

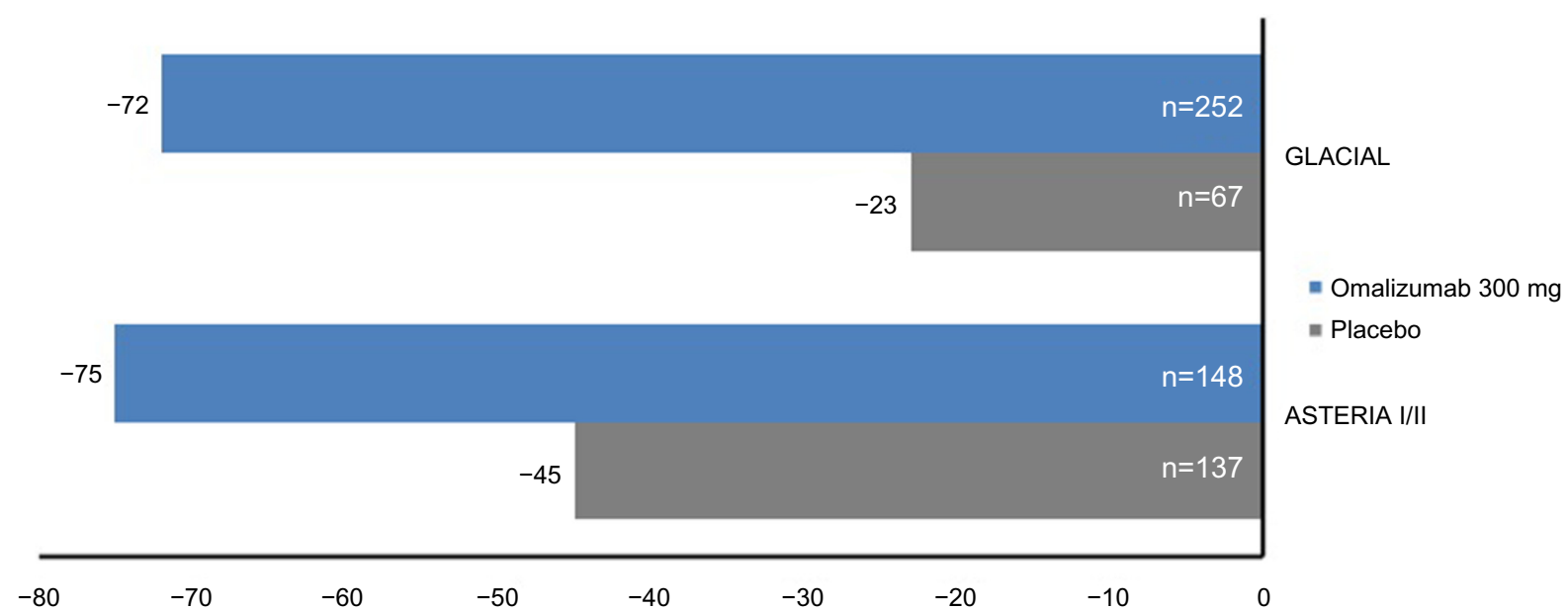

Mean reduction from baseline to week $12(\%)$

\begin{tabular}{|l|c|c|}
\hline & ASTERIA I/II & GLACIAL \\
\hline $\begin{array}{l}\text { Difference vs placebo } \\
(95 \% \mathrm{Cl})^{*}\end{array}$ & $30(18-41)$ & $50(36-64)$ \\
\hline
\end{tabular}

Figure 3 Percentage reduction from baseline to week I2 in DLQI score.

Note: Significant treatment differences in change from baseline to week 12 in DLQI score were observed with omalizumab 300 mg versus placebo in the pool ASTERIA I/ II and GLACIAL studies. *Treatment difference in least squares means (LSM) relative to placebo. Data from Bernstein JA, Saini SS, Maurer M, et al. Efficacy of omalizumab in patients with chronic idiopathic/spontaneous urticaria with different background therapy: post hoc analysis of ASTERIA I, ASTERIA II, and GLACIAL studies. J Allergy Clin Immunol. 2014;133(2 Suppl):AB I 17.34

Abbreviations: $\mathrm{Cl}$, confidence interval; DLQI, Dermatology Life Quality Index. 


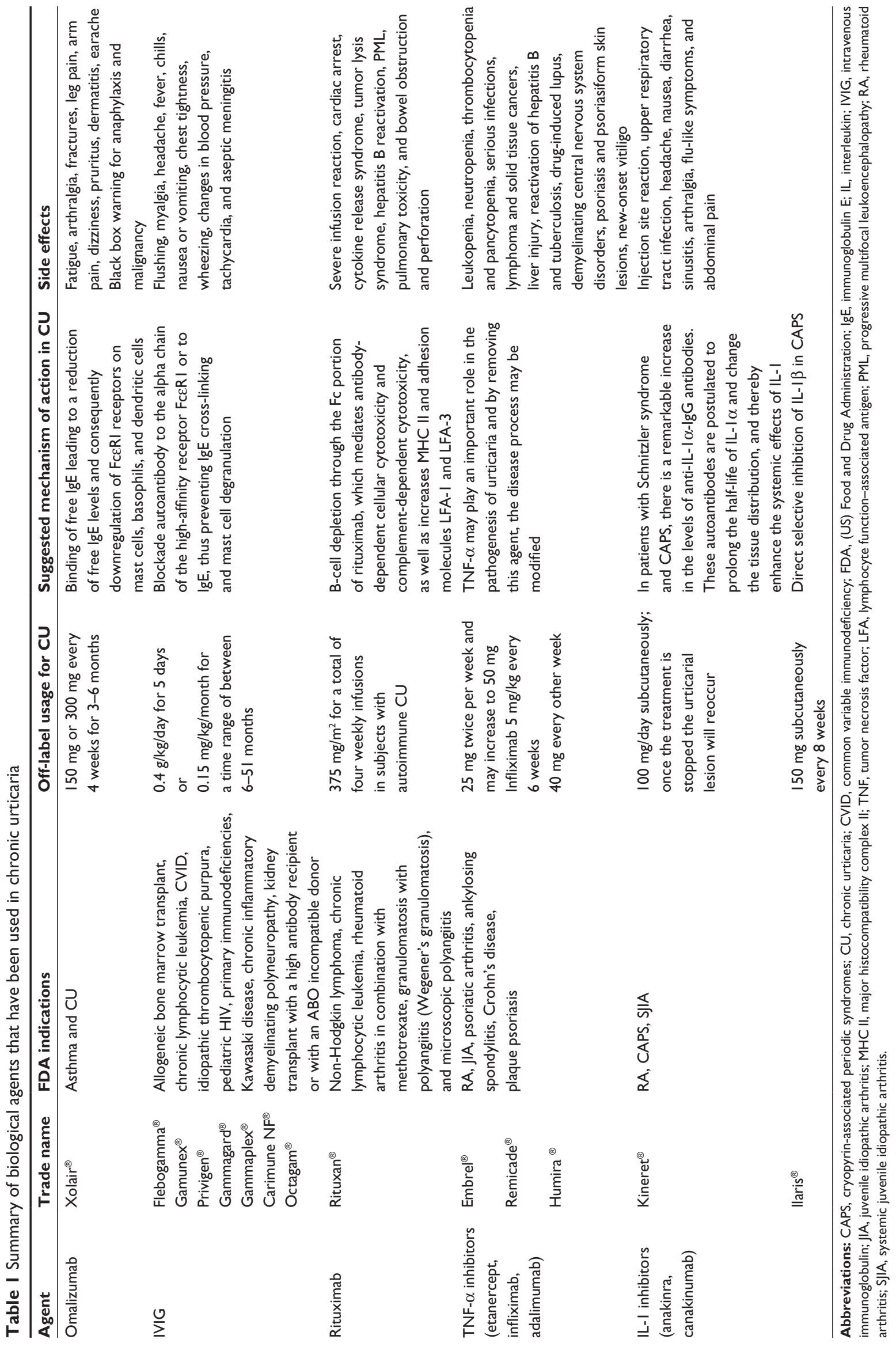


as replacement therapy for immunodeficient subjects as well as an immune modulator in subjects with autoimmune conditions. ${ }^{37}$ IVIG appears to have multiple mechanisms of action for immunoregulatory effects, including Fc receptor blockade, enhancement of regulatory $\mathrm{T}$ cells, accelerated clearance of autoantibodies, and increase in Fc $\gamma$ RIIB expression. ${ }^{36,38,39}$ These mechanisms likely account for its efficacy in autoimmune diseases such as Guillain-Barré syndrome, idiopathic thrombocytopenia, and myasthenia gravis. ${ }^{40}$ In CU, approximately $40 \%-50 \%$ of patients have autoantibodies to the alpha chain of the high-affinity receptor FceR1 or to IgE. 1,41,42 These autoantibodies can often be demonstrated by an autologous serum skin test (ASST) indicating that these subjects have a serum component that causes mast cell degranulation. ${ }^{41-43}$ However, the exact relationship between the presence of these and other autoantibodies and the pathogenesis of $\mathrm{CU}$ remains to be determined. Nonetheless, the use of IVIG has been espoused based on the known therapeutic effects of IVIG in autoimmune diseases.

One of the first trials supporting the potential therapeutic effects of IVIG was performed in the early 1990s by Grattan et al using plasmapheresis in eight subjects with severe CU and histamine-releasing activity in their sera. ${ }^{44}$ Of the eight subjects, four responded transiently and two had complete remission. ${ }^{44}$ These data suggested an important pathogenic role of these autoantibodies in some patients. O'Donnell et al used the results of Grattan et al's trial as evidence to support a subsequent trial for using IVIG in CU with autoantibodies. O'Donnell et al studied ten subjects with severe autoimmune CU and treated them with $0.4 \mathrm{~g} / \mathrm{kg} /$ day of IVIG for 5 days. ${ }^{41}$ Clinical benefit was seen in nine of ten patients, with three patients achieving complete remission at 3 years' follow-up. ${ }^{41}$ Another group also evaluated the utility of IVIG in subjects with autoimmune CU with monthly infusions of low-dose IVIG $(0.15 \mathrm{mg} / \mathrm{kg})$ for $6-51$ months. The response rate was close to $90 \%$ and $65 \%$ achieved complete remission. ${ }^{45}$ Unfortunately, not all patients achieve an adequate response to IVIG. Asero published a case series of three patients suffering from severe CU who had either no response or only temporary relief from IVIG. ${ }^{46}$ Beyond CU, IVIG has also been shown to be efficacious in subjects with solar urticaria, defined as urticarial rash developing within minutes of skin exposure to sunlight. ${ }^{9}$ This disorder has also been reported to have a passive transfer factor in some patients that could be a target for IVIG. A retrospective analysis of seven subjects with solar urticaria treated with IVIG found that five of the seven had complete remission.
Case reports have also shown efficacy of IVIG in solar urticaria. ${ }^{47,48}$ More recently, Aubin et al studied nine subjects with antihistamine-refractory solar urticaria. Subjects were treated with $1 \mathrm{~g} / \mathrm{kg} /$ day for 2 days, and then evaluated at 4 and 12 weeks. Of the nine subjects, only two showed remission of solar urticaria at 4 and 12 weeks. ${ }^{49}$ IVIG side effects can include flushing, myalgia, headache, fever, chills, nausea or vomiting, chest tightness, wheezing, changes in blood pressure, tachycardia, and aseptic meningitis. ${ }^{49}$ The data to date suggest that IVIG may work in some CU patients with autoantibodies. However, the costs, side-effect profile, and need for IV access make it a less favorable choice for management of $\mathrm{CU}$.

\section{Rituximab}

Rituximab is a chimeric murine/human monoclonal antibody directed against CD20 that is currently approved by the FDA for treatment of non-Hodgkin lymphoma, chronic lymphocytic leukemia, rheumatoid arthritis in combination with methotrexate, granulomatosis with polyangiitis (Wegener's granulomatosis), and microscopic polyangiitis. The mechanism of action of rituximab in CU is believed to be due to the inhibitory effect of the medication on autoantibody production. ${ }^{50}$ Rituximab has had mixed results in a variety of published reports. A report of a subject with pressure-induced urticaria of the hands and feet and spontaneous urticaria and angioedema who failed first and second line of treatment received rituximab infusions of $375 \mathrm{mg} / \mathrm{m}^{2}$ for a total of four weekly infusions. The subject experienced no benefit on rituximab. ${ }^{50}$ Since that report, there have been a few additional case reports with more positive results. In 2009, a case of refractory CU and immunodeficiency was given four infusions of rituximab $375 \mathrm{mg} / \mathrm{m}^{2}$, and was symptom free within 1 week. The symptom-free duration lasted for over 1 year afterward and was easily managed with antihistamines. ${ }^{51}$ In another case of refractory chronic autoimmune urticaria, a patient received four weekly doses of rituximab and methotrexate, and after 6 weeks of the last infusion, the subject achieved complete remission. ${ }^{52}$ Beyond $\mathrm{CU}$, rituximab has shown benefit in hypocomplementemic urticarial vasculitis (HUVS). ${ }^{53}$ A case report of a patient with urticarial vasculitis who failed immunomodulator therapy and corticosteroids was treated with four weekly $375 \mathrm{mg} / \mathrm{m}^{2}$ doses of rituximab. The subject experienced complete resolution of HUVS following this therapy. ${ }^{53}$ Thus, there are a few reports of the therapeutic utility of rituximab in $\mathrm{CU}$, but no randomized, blinded trials have been carried out, indicating low-grade evidence to support its use. 


\section{TNF- $\alpha$ inhibitors}

Three biologic TNF- $\alpha$ inhibitors, etanercept, infliximab, and adalimumab, have been used in the treatment of either $\mathrm{CU}$ or urticarial vasculitis based on the postulate that TNF- $\alpha$ may play an important role in the pathogenesis of some cases of urticaria. ${ }^{54,55}$ Etanercept and adalimumab are both given as subcutaneous injections, while infliximab is given as an infusion. One of the first instances of TNF- $\alpha$ inhibitor usage in urticaria was in a case of refractory delayed pressure urticaria and psoriasis. Etanercept was started at the recommended dose of $25 \mathrm{mg}$ twice per week for psoriasis. ${ }^{56}$ By the fifth day of therapy, the patient's delayed pressure urticaria remitted; the therapeutic benefit persisted during treatment. The patient was subsequently switched to infliximab due to progression of his psoriasis. Since the first dose of a TNF blocker, the subject has remained symptom free from delayed pressure urticaria. ${ }^{56} \mathrm{In}$ 2011, a case series of six patients with either CIU or urticarial vasculitis were treated with a TNF- $\alpha$ inhibitor. In all cases, the subjects experienced dramatic improvement. ${ }^{57}$ Regardless of the specific medication, these TNF- $\alpha$ inhibitors all carry the risk of serious infections, including tuberculosis and fungal infections. Additionally, they carry a risk for lymphomas and other malignancies. These agents should not be started if a patient has an active malignancy or infection, as these medications could worsen those conditions. Overall, the evidence supporting the use of TNF- $\alpha$ blockers is limited by the small numbers of patients in noncontrolled studies, often with urticarial disorders not typical of CU such as vasculitis and delayed pressure urticaria. Thus, it is hard to recommend these agents until better controlled trials are performed and the results are compared to omalizumab, which has a better side-effect profile.

\section{IL-I inhibitors}

As more information is learned about $\mathrm{CU}$, we are increasingly recognizing the heterogeneity of the disease. Perhaps, as we learn more, specific biologics can find a niche for certain types of patients, as has been demonstrated for anakinra and other interleukin (IL)-1 blockers (eg, canakinumab) with Schnitzler syndrome and CAPS.

Anakinra is a recombinant human interleukin-1 receptor antagonist (IL-1 Ra) that is currently approved by the FDA for rheumatoid arthritis patients aged 18 years or older who have failed one or more disease-modifying antirheumatic drugs (DMARDS) and CAPS. The agent works by inhibiting IL-1 binding to its IL-1 type I receptor (IL-1R1)..$^{58}$

Canakinumab is a fully human anti-IL- $1 \beta$ monoclonal antibody that selectively blocks IL-1 $\beta$ and has no cross-reactivity with other characterized IL-1 family members, including IL- $1 \alpha$ and IL-1 Ra ${ }^{59}$ It is approved by the FDA for adults and children 4 years of age and older who have CAPS and SJIA.

CAPS is a spectrum of autoinflammatory syndromes including familial cold autoinflammatory syndrome (FCAS, formerly termed familial cold-induced urticaria), MuckleWells syndrome (MWS), and neonatal-onset multisystem inflammatory disease (NOMID, also called chronic infantile neurologic cutaneous and articular syndrome [CINCA] $)^{60}$ CAPS are generally caused by autosomal-dominant mutations of the NLRP3 (nucleotide-binding domain, leucine-rich family [NLR], pyrin domain containing 3 ) gene (formerly known as the cold-induced autoinflammatory syndrome 1 [CIAS1] gene) and resultant alterations in the protein cryopyrin, which NLRP3 encodes ${ }^{60,61}$ Cryopyrin is critical to the production of IL-1 $\beta$; alterations in cryopyrin lead to IL-1 $\beta$ overproduction, resulting in an inflammatory response and the symptoms of CAPS. ${ }^{6}$ In a randomized, double-blinded, placebo-controlled trial involving 35 subjects with CAPS, $>95 \%$ of patients who received canakinumab achieved complete remission. ${ }^{63}$ All of the 15 subjects who continued the treatment remained in remission and $81 \%$ who switched to placebo had flare-ups. ${ }^{63}$

Schnitzler syndrome is a rare condition initially described in 1974 by a French rheumatologist, Liliane Schnitzler. In this condition, $100 \%$ of subjects have an urticarial rash, which is often accompanied by fevers, myalgias, elevated erythrocyte sedimentation rate, enlarged lymph nodes, and monoclonal IgM. ${ }^{64}$ The exact cause of the condition is unknown; however, IL-1 is suggested to play a critical role in the disease due to the dramatic response subjects have to anakinra. ${ }^{65,66} \mathrm{~A}$ recent French nationwide retrospective analysis of 29 subjects with Schnitzler syndrome treated with anakinra found that all patients responded to the treatment, with $83 \%$ achieving complete remission and the remaining $17 \%$ attaining partial remission. Three patients developed grade 3-4 neutropenia, and six developed severe infections. ${ }^{67}$ A Cochrane analysis of anakinra in rheumatoid arthritis found that while serious infections were clinically higher than placebo, this was not statistically significant. ${ }^{68} \mathrm{~A}$ similar analysis has not been done for urticarial conditions.

\section{Conclusion}

Evidence has shown that biologic agents have therapeutic potential in some patients with antihistamine-resistant urticaria. Omalizumab is the first biologic to be approved for the treatment of CIU by the FDA and has been shown 
to have both excellent efficacy and safety profiles. Other biologics are less well studied, but have an important role in specific types of urticarial disorders such as anakinra in Schnitzler syndrome. While each of these agents has a different side-effect profile and mechanism of action, they can be expensive and difficult to afford if the patient pays out-of-pocket. In spite of costs, as medicine advances, biologics are likely to play a larger role in the urticarial diseases as a form of tailored therapy to a subject, specific urticarial disease.

\section{Disclosure}

Dr Cooke and Dr Bulkhi have no conflicts of interest to disclose. Dr Casale has been an investigator on grants from Genentech and Novartis and has been on advisory boards for Novartis and Genentech with all funds to his University employers.

\section{References}

1. Zuberbier T, Aberer W, Asero R, et al; European Academy of Allergy and Clinical Immunology; Global Allergy and Asthma European Network; European Dermatology Forum; World Allergy Organization. The EAACI/GA(2) LEN/EDF/WAO Guideline for the definition, classification, diagnosis, and management of urticaria: the 2013 revision and update. Allergy. 2014;69(7):868-887.

2. O'Donnell BF, Lawlor F, Simpson J, Morgan M, Greaves MW. The impact of chronic urticaria on the quality of life. Br J Dermatol. 1997; 136(2):197-201.

3. Khan DA. Chronic urticaria: diagnosis and management. Allergy Asthma Proc. 2008;29(5):439-446.

4. Engin B, Uguz F, Yilmaz E, Ozdemir M, Mevlitoglu I. The levels of depression, anxiety and quality of life in patients with chronic idiopathic urticaria. J Eur Acad Dermatol Venereol. 2008;22(1):36-40.

5. Kaplan AP. Treatment of chronic spontaneous urticaria. Allergy Asthma Immunol Res. 2012;4(6):326-331.

6. Powell RJ, Du Toit GL, Siddique N, et al; British Society for Allergy and Clinical Immunology (BSACI). BSACI guidelines for the management of chronic urticaria and angio-oedema. Clin Exp Allergy. 2007;37(5): 631-650.

7. Greaves M. Chronic urticaria. J Allergy Clin Immunol. 2000;105(4): 664-672.

8. Maurer M, Weller K, Bindslev-Jensen C, et al. Unmet clinical needs in chronic spontaneous urticaria. A GA ${ }^{2} \mathrm{LEN}$ task force report. Allergy. 2011;66(3):317-330.

9. Bernstein JA, Lang DM, Khan DA, et al. The diagnosis and management of acute and chronic urticaria: 2014 update. J Allergy Clin Immunol. 2014;133(5):1270-1277.

10. Humphreys F, Hunter JA. The characteristics of urticaria in 390 patients. Br J Dermatol. 1998;138(4):635-638.

11. Normansell R, Walker S, Milan SJ, Walters EH, Nair P. Omalizumab for asthma in adults and children. Cochrane Database Syst Rev. 2014;1:CD003559.

12. Easthope S, Jarvis B. Omalizumab. Drugs. 2001;61(2):253-260; discussion 261.

13. Kaplan AP. Therapy of chronic urticaria: a simple, modern approach. Ann Allergy Asthma Immunol. 2014;112(5):419-425.

14. Niimi N, Francis DM, Kermani F, et al. Dermal mast cell activation by autoantibodies against the high affinity IgE receptor in chronic urticaria. J Invest Dermatol. 1996;106(5):1001-1006.
15. Holgate ST, Djukanovic R, Casale T, Bousquet J. Anti-immunoglobulin E treatment with omalizumab in allergic diseases: an update on antiinflammatory activity and clinical efficacy. Clin Exp Allergy. 2005; 35(4):408-416.

16. Saavedra MC, Sur S. Down regulation of the high-affinity IgE receptor associated with successful treatment of chronic idiopathic urticaria with omalizumab. Clin Mol Allergy. 2011;9(1):2.

17. Chang TW, Chen C, Lin CJ, Metz M, Church MK, Maurer M. The potential pharmacologic mechanisms of omalizumab in patients with chronic spontaneous urticaria. J Allergy Clin Immunol. 2015; 135(2):337-342. e2.

18. Kawakami T, Galli SJ. Regulation of mast-cell and basophil function and survival by IgE. Nat Rev Immunol. 2002;2(10):773-786.

19. Boyce JA. Successful treatment of cold-induced urticaria/anaphylaxis with anti-IgE. J Allergy Clin Immunol. 2006;117(6):1415-1418.

20. Sands MF, Blume JW, Schwartz SA. Successful treatment of 3 patients with recurrent idiopathic angioedema with omalizumab. JAllergy Clin Immunol. 2007;120(4):979-981.

21. Spector SL, Tan RA. Effect of omalizumab on patients with chronic urticaria. Ann Allergy Asthma Immunol. 2007;99(2):190-193.

22. Vestergaard C, Deleuran M. Two cases of severe refractory chronic idiopathic urticaria treated with omalizumab. Acta Derm Venereol. 2010;90(4):443-444.

23. Romano C, Sellitto A, De Fanis U, et al. Maintenance of remission with low-dose omalizumab in long-lasting, refractory chronic urticaria. Ann Allergy Asthma Immunol. 2010;104(1):95-97.

24. Metz M, Ohanyan T, Church MK, Maurer M. Omalizumab is an effective and rapidly acting therapy in difficult-to-treat chronic urticaria: a retrospective clinical analysis. J Dermatol Sci. 2014;73(1):57-62.

25. Altman MC, Naimi DR. Omalizumab for chronic urticaria. $N$ Engl $J$ Med. 2013;368(26):2528-2530.

26. Brodska P, Schmid-Grendelmeier P. Treatment of severe cold contact urticaria with omalizumab: case reports. Case Rep Dermatol. 2012;4(3):275-280.

27. Saini SS, Bindslev-Jensen C, Maurer M, et al. Efficacy and safety of omalizumab in patients with chronic idiopathic/spontaneous urticaria who remain symptomatic on $\mathrm{H}$ antihistamines: a randomized, placebocontrolled study. J Invest Dermatol. 2015;135(1):67-75.

28. Metz M, Bergmann P, Zuberbier T, Maurer M. Successful treatment of cholinergic urticaria with anti-immunoglobulin E therapy. Allergy. 2008;63(2):247-249.

29. Kaplan AP, Joseph K, Maykut RJ, Geba GP, Zeldin RK. Treatment of chronic autoimmune urticaria with omalizumab. J Allergy Clin Immunol. 2008;122(3):569-573.

30. Maurer M, Altrichter S, Bieber T, et al. Efficacy and safety of omalizumab in patients with chronic urticaria who exhibit IgE against thyroperoxidase. J Allergy Clin Immunol. 2011;128(1):202-209. e5.

31. Saini S, Rosen KE, Hsieh HJ, et al. A randomized, placebo-controlled, dose-ranging study of single-dose omalizumab in patients with H1-antihistamine-refractory chronic idiopathic urticaria. J Allergy Clin Immunol. 2011;128(3):567-573. e1.

32. Maurer M, Rosen K, Hsieh HJ, et al. Omalizumab for the treatment of chronic idiopathic or spontaneous urticaria. N Engl J Med. 2013; 368(10):924-935.

33. Kaplan A, Ledford D, Ashby M, et al. Omalizumab in patients with symptomatic chronic idiopathic/spontaneous urticaria despite standard combination therapy. J Allergy Clin Immunol. 2013;132(1):101-109.

34. Bernstein JA, Saini SS, Maurer M, et al. Efficacy of omalizumab in patients with chronic idiopathic/spontaneous urticaria with different background therapy: post hoc analysis of ASTERIA I, ASTERIA II, and GLACIAL studies. J Allergy Clin Immunol. 2014;133(2 Suppl):AB117.

35. Metz M, Ohanyan T, Church MK, Maurer M. Retreatment with omalizumab results in rapid remission in chronic spontaneous and inducible urticaria. JAMA Dermatol. 2014;150(3):288-290.

36. Schwab I, Nimmerjahn F. Intravenous immunoglobulin therapy: how does IgG modulate the immune system? Nat Rev Immunol. 2013;13(3): 176-189. 
37. Ballow M. Mechanisms of immune regulation by IVIG. Curr Opin Allergy Clin Immunol. 2014;14(6):509-515.

38. Negi VS, Elluru S, Siberil S, et al. Intravenous immunoglobulin: an update on the clinical use and mechanisms of action. J Clin Immunol. 2007;27(3):233-245.

39. Ballow M. The IgG molecule as a biological immune response modifier: mechanisms of action of intravenous immune serum globulin in autoimmune and inflammatory disorders. J Allergy Clin Immunol. 2011;127(2):315-323; quiz 324-315.

40. Neunert C, Lim W, Crowther M, Cohen A, Solberg L Jr, Crowther MA; American Society of Hematology. The American Society of Hematology 2011 evidence-based practice guideline for immune thrombocytopenia. Blood. 2011;117(16):4190-4207.

41. O'Donnell BF, Barr RM, Black AK, et al. Intravenous immunoglobulin in autoimmune chronic urticaria. Br J Dermatol. 1998;138(1): $101-106$.

42. Watkins C, Peiris E, Saleh H, Krishnaswamy G. Intravenous immunoglobulin as a potential therapy for refractory urticaria - a review. Inflamm Allergy Drug Targets. 2012;11(5):375-381.

43. Hide M, Francis DM, Grattan CE, Hakimi J, Kochan JP, Greaves MW. Autoantibodies against the high-affinity $\operatorname{IgE}$ receptor as a cause of histamine release in chronic urticaria. $N$ Engl J Med. 1993;328(22): 1599-1604.

44. Grattan CE, Francis DM, Slater NG, Barlow RJ, Greaves MW. Plasmapheresis for severe, unremitting, chronic urticaria. Lancet. 1992;339(8801):1078-1080.

45. Pereira C, Tavares B, Carrapatoso I, et al. Low-dose intravenous gammaglobulin in the treatment of severe autoimmune urticaria. Eur Ann Allergy Clin Immunol. 2007;39(7):237-242.

46. Asero R. Are IVIG for chronic unremitting urticaria effective? Allergy. 2000;55(11):1099-1101

47. Correia I, Silva J, Filipe P, Gomes M. Solar urticaria treated successfully with intravenous high-dose immunoglobulin: a case report. Photodermatol Photoimmunol Photomed. 2008;24(6):330-331.

48. Darras S, Segard M, Mortier L, Bonnevalle A, Thomas P. Urticaire solaire traitée par l'association immunoglobulines polyvalentes et PUVAthérapie. [Treatment of solar urticaria by intravenous immunoglobulins and PUVA therapy]. Ann Dermatol Venereol. 2004;131(1 Pt 1): 65-69. French.

49. Aubin F, Porcher R, Jeanmougin M, et al; Société Française de Photodermatologie. Severe and refractory solar urticaria treated with intravenous immunoglobulins: a phase II multicenter study. $\mathrm{J} \mathrm{Am} \mathrm{Acad}$ Dermatol. 2014;71(5):948-953. e1.

50. Mallipeddi R, Grattan CE. Lack of response of severe steroiddependent chronic urticaria to rituximab. Clin Exp Dermatol. 2007; 32(3):333-334.

51. Arkwright PD. Anti-CD20 or anti-IgE therapy for severe chronic autoimmune urticaria. J Allergy Clin Immunol. 2009;123(2):510-511; author reply 511

52. Chakravarty SD, Yee AF, Paget SA. Rituximab successfully treats refractory chronic autoimmune urticaria caused by $\operatorname{IgE}$ receptor autoantibodies. J Allergy Clin Immunol. 2011;128(6):1354-1355.
53. Saigal K, Valencia IC, Cohen J, Kerdel FA. Hypocomplementemic urticarial vasculitis with angioedema, a rare presentation of systemic lupus erythematosus: rapid response to rituximab. JAm Acad Dermatol. 2003;49(5 Suppl):S283-S285.

54. Hermes B, Prochazka AK, Haas N, Jurgovsky K, Sticherling M, Henz BM. Upregulation of TNF-alpha and IL-3 expression in lesional and uninvolved skin in different types of urticaria. J Allergy Clin Immunol. 1999;103(2 Pt 1):307-314.

55. Piconi $\mathrm{S}$, Trabattoni $\mathrm{D}$, Iemoli $\mathrm{E}$, et al. Immune profiles of patients with chronic idiopathic urticaria. Int Arch Allergy Immunol. 2002;128(1): 59-66.

56. Magerl M, Philipp S, Manasterski M, Friedrich M, Maurer M. Successful treatment of delayed pressure urticaria with anti-TNF-alpha. J Allergy Clin Immunol. 2007;119(3):752-754.

57. Wilson LH, Eliason MJ, Leiferman KM, Hull CM, Powell DL. Treatment of refractory chronic urticaria with tumor necrosis factor-alfa inhibitors. J Am Acad Dermatol. 2011;64(6):1221-1222.

58. Hannum CH, Wilcox CJ, Arend WP, et al. Interleukin-1 receptor antagonist activity of a human interleukin-1 inhibitor. Nature. 1990; 343(6256):336-340.

59. Alten R, Gram H, Joosten LA, et al. The human anti-IL-1 beta monoclonal antibody ACZ885 is effective in joint inflammation models in mice and in a proof-of-concept study in patients with rheumatoid arthritis. Arthritis Res Ther. 2008;10(3):R67.

60. Federici S, Sormani MP, Ozen S, et al; for the Paediatric Rheumatology International Trials Organisation (PRINTO) and Eurofever Project. Evidence-based provisional clinical classification criteria for autoinflammatory periodic fevers. Ann Rheumat Dis. Epub January 30, 2015.

61. Hoffman HM, Mueller JL, Broide DH, Wanderer AA, Kolodner RD. Mutation of a new gene encoding a putative pyrin-like protein causes familial cold autoinflammatory syndrome and Muckle-Wells syndrome. Nat Genet. 2001;29(3):301-305.

62. Church LD, Cook GP, McDermott MF. Primer: inflammasomes and interleukin 1 beta in inflammatory disorders. Nat Clin Pract Rheumatol. 2008;4(1):34-42.

63. Lachmann HJ, Kone-Paut I, Kuemmerle-Deschner JB, et al. Use of canakinumab in the cryopyrin-associated periodic syndrome. $N$ Engl $J$ Med. 2009;360(23):2416-2425.

64. Simon A, Asli B, Braun-Falco M, et al. Schnitzler's syndrome: diagnosis, treatment, and follow-up. Allergy. 2013;68(5):562-568.

65. Lipsker D. The Schnitzler syndrome. Orphanet J Rare Dis. 2010; $5: 38$.

66. Lachmann HJ, Hawkins PN. Developments in the scientific and clinical understanding of autoinflammatory disorders. Arthritis Res Ther 2009;11(1):212.

67. Neel A, Henry B, Barbarot S, et al. Long-term effectiveness and safety of interleukin-1 receptor antagonist (anakinra) in Schnitzler's syndrome: a French multicenter study. Autoimmun Rev. 2014;13(10):1035-1041.

68. Mertens M, Singh JA. Anakinra for rheumatoid arthritis. Cochrane Database Syst Rev. 2009;(1):CD005121.
Biologics: Targets \& Therapy

\section{Publish your work in this journal}

Biologics: Targets \& Therapy is an international, peer-reviewed journal focusing on the patho-physiological rationale for and clinical application of Biologic agents in the management of autoimmune diseases, cancers or other pathologies where a molecular target can be identified This journal is indexed on PubMed Central, CAS, EMBase, Scopus

\section{Dovepress}

and the Elsevier Bibliographic databases. The manuscript management system is completely online and includes a very quick and fair peerreview system, which is all easy to use. Visit http://www.dovepress. com/testimonials.php to read real quotes from published authors. 